\title{
DOI: 10.20472/IAC.2017.031.034
}

\author{
HANAN MUHAYA ALENAZY \\ University of Leicester, United Kingdom
}

\section{THE CONSTRUCTION OF GENDER IN SAUDI ARABIA}

\begin{abstract}
:
Gender equality is a controversial issue and has been a constant subject of debate across the world in varied domains and disciplines, particularly in the field of Higher Education (HE). Several scholars distinguish between the terms gender and sex. They believe that gender is a social construct and learnt behaviour, while sex is perceived as a biological category (McHugh 2007). Such differences in gender can be viewed as a cultural phenomenon, generating from the dominant concepts of a specific culture or era (Weiner 2010).
\end{abstract}

It is argued that Muslim women are enslaved through oppression and inequality (Aquil 2012). Such inequality can be recognised in varied forms, for instance, their underrepresentation in several areas of achievement and progress particularly in acceding to senior management positions in academia. It seems that there is no exception for women in Saudi Arabia either, who might encounter such issues. Certain factors can be attributed to why women, particularly in Saudi Arabia, are not accorded career progression like their male counterparts, the primary one being the fact that $60 \%$ of Saudi women are homemakers (Alharbi 2014). Therefore, the aim of this paper is to investigate the intersection and influence of wider social discourses, religion, culture, and traditions on the role of Saudi women at work and exploring the nature and root causes of discrimination.

My research methodology utilised a qualitative approach in the form of multiple case studies. This research was performed from a feminist standpoint. Feminist research brings gender to the foreground and endeavours to understand social phenomena from the perspective of women (Cohen et al. 2013). Similarly, as stated by Lather (1998) a leading scholar in feminist research, the purpose of such ideological study is to 'correct both the invisibility and distortion of female experience in ways relevant to ending women's unequal social position'.

The research sample comprised 25 participants, all female academics from five state universities, selected intentionally for this research, who had either been promoted to leadership positions or not. Additionally, there were five male participants who were considered key informants, closely connected with the formulation and implementation of policies in HE institutions in Saudi Arabia.

This paper addresses the following question:

To what extent are the obstacles that Saudi female academics face within the university, a reflection of the influence of wider social discourses, religion, cultures, and traditions on the role of Saudi working women?

\section{Keywords:}

Gender construction, Saudi women, wider social discourses, religion, cultures, and traditions.

JEL Classification: Z12, D63, Z18 